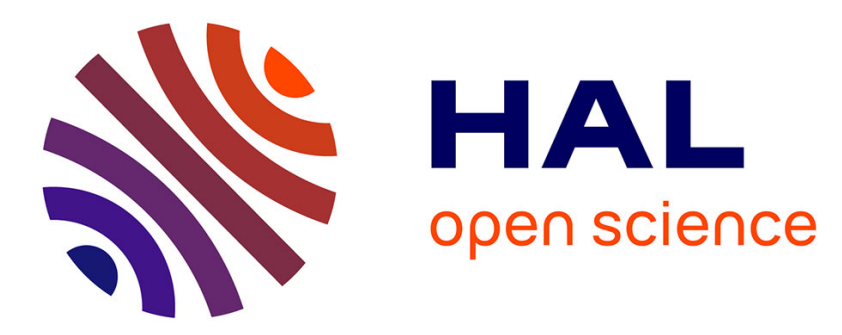

\title{
Stress-induced amorphization triggers deformation in the lithospheric mantle
}

Vahid Samae, Patrick Cordier, Sylvie Demouchy, Caroline Bollinger, Julien

Gasc, Sanae Koizumi, Alexandre Mussi, Dominique Schryvers, Hosni Idrissi

\section{- To cite this version:}

Vahid Samae, Patrick Cordier, Sylvie Demouchy, Caroline Bollinger, Julien Gasc, et al.. Stress-induced amorphization triggers deformation in the lithospheric mantle. Nature, 2021, 591 (7848), pp.82-86. 10.1038/s41586-021-03238-3 . hal-03160173

\section{HAL Id: hal-03160173 \\ https://hal.univ-lille.fr/hal-03160173}

Submitted on 5 Mar 2021

HAL is a multi-disciplinary open access archive for the deposit and dissemination of scientific research documents, whether they are published or not. The documents may come from teaching and research institutions in France or abroad, or from public or private research centers.
L'archive ouverte pluridisciplinaire HAL, est destinée au dépôt et à la diffusion de documents scientifiques de niveau recherche, publiés ou non, émanant des établissements d'enseignement et de recherche français ou étrangers, des laboratoires publics ou privés. 


\title{
Stress-induced amorphization triggers deformation in the lithospheric mantle
}

\author{
Vahid Samae ${ }^{1}$, Patrick Cordier ${ }^{2,3}{ }^{\natural}$, Sylvie Demouchy ${ }^{4}$, Caroline Bollinger ${ }^{5, *}$, Julien Gasc ${ }^{4,+}$,
} Sanae Koizumi ${ }^{6}$, Alexandre Mussi ${ }^{2}$, Dominique Schryvers ${ }^{1}$ \& Hosni Idrissi ${ }^{7,1}$

Received: 3 February 2020

Accepted: 13 January 2021

Published: 3 March 2021

Cite as:

V. Samae, P. Cordier, S. Demouchy, C. Bollinger, J. Gasc, S. Koizumi, A. Mussi, D. Schryvers \& H. Idrissi (2021) Stressinduced amorphization triggers deformation in the lithospheric mantle. Nature 591, 82-86

Final version at: https://doi.org/10.1038/s41586-021$\underline{03238-3}$
The mechanical properties of olivine-rich rocks are central to decipher the partial mechanical coupling between the lithosphere and asthenosphere. In crystalline materials, the motion of crystal defects is fundamental to plastic flow ${ }^{1-}$ 4. Olivine-rich rocks are facing the issue that their main constituent does not have enough slip systems to satisfy general strain conditions. Therefore, additional deformation mechanisms are needed. Recent experimental studies in rock physics have brought forward a non-Newtonian, grain size sensitive, mechanism in olivine involving grain boundary sliding (GBS) ${ }^{5,6}$. Nevertheless, very few microstructural investigations have been conducted on GBS and there is still no consensus on whether a single or multiple physical mechanisms are at play. Most importantly, to date no theoretical framework is available to incorporate grain boundary mechanics in polycrystalline plasticity models. Here we identify such a mechanism. We show for the first time that in forsterite, amorphization takes place at grain boundaries under stress and that the onset of ductility of olivine-rich rocks is due to the activation of grain boundary mobility on these amorphous layers. We propose that this mechanism can trigger plastic processes in the deep Earth where high stress conditions are encountered (e.g. at the brittle-plastic transition). The implications will be maximal in the lithosphere-asthenosphere transition layer, where a viscosity drop can be triggered by the glass transition temperature of amorphous olivine, promoting GBS.
Different kinds of crystal defects are usually involved in the plastic flow of rocks. Atomic mobility promoted by vacancies can be the cause for diffusion creep provided the grain size is small enough $(<100$ microns). This deformation regime is linear Newtonian. For larger grain sizes ( $>500$ microns), the motion of linear crystal defects, dislocations, is responsible for the dislocation creep. This latter regime is grain-size insensitive and exhibits a marked stress sensitivity described by a power law at high temperature and an exponential law at lower temperatures ${ }^{1-3}$. Grain boundaries are another class of defects which are less well understood ${ }^{4}$. In 1995, Hirth and Kohlstedt ${ }^{5}$ defined a non-Newtonian deformation regime involving grain boundary sliding (GBS), which, although grain size sensitive, was not known previously in olivine. This grain size sensitive mechanism may be important in inducing strain localization in the lithosphere ${ }^{6}$. GBS is identified by displacements across grain boundaries which have been observed in high-temperature deformation experiments in the diffusion creep regime ${ }^{7}$, and in the dislocation creep regime ${ }^{8}$. Grain boundary sliding also operates under high confining pressure (3-5 $\mathrm{GPa})$ relevant for the base of the continental

\footnotetext{
$\diamond$ Corresponding author : Patrick Cordier (Patrick.cordier@univ-lille.fr) - ORCID: 0000-0002-1883-2994. ${ }^{1}$ Electron Microscopy for Materials Science, University of Antwerp, Antwerp, Belgium. ${ }^{2}$ Univ. Lille, CNRS, INRAE, Centrale Lille, UMR 8207 - UMET - Unité Matériaux et Transformations, F59000 Lille, France. ${ }^{3}$ Institut Universitaire de France, 1 rue Descartes, F-75005 Paris, France. ${ }^{4}$ Géosciences Montpellier, Université de Montpellier and CNRS, UMR 5243, Montpellier, France. ${ }^{5}$ Bayerisches Geoinstitut, Universität Bayreuth, D-95445 Bayreuth, Germany. ${ }^{6}$ Earthquake Research Institute, University of Tokyo, Tokyo, Japan. ${ }^{7}$ Institute of Mechanics, Materials and Civil Engineering, UCLouvain, Louvain-la-Neuve, Belgium. * Now at IRAP, Université de Toulouse, CNRS, CNES, UPS, F-31400 Toulouse, France. ${ }^{+}$Now at Laboratoire de Géologie, École Normale Supérieure and CNRS, UMR8538, Paris, France
} 
lithosphere ${ }^{8-10}$. In the present paper, by GBS, we refer to the elementary deformation process that involves a rigid shear displacement of a grain relative to a neighbouring grain. Traditionally, sliding refers to a displacement parallel to the boundary plane. This does not exclude a component of displacement normal to the boundary (migration) since both are often coupled ${ }^{11}$. In an aggregate, GBS leads to incompatibilities. This phenomenon is encountered when boundaries are not perfectly planar ${ }^{12}$, but also at triple junctions. When strains remain small $\left(10^{-6}\right)$ as during forced-oscillation experiments to measure anelasticity ${ }^{13}$, incompatibilities can be accommodated elastically. This important case which contributes to the anelastic behaviour of the Earth mantle ${ }^{13}, 14$, is not considered in the present study. For larger strains (several \%), GBS can only proceed if other deformation mechanisms are activated to release these incompatibilities. These mechanisms can be either diffusive or involve dislocations and yield to creep behaviours which are usually referred as to diffusion- or dislocation-accommodated GBS creep. This terminology is, however, rather confusing since all mechanisms should be considered concomitant with no intrinsic hierarchy between them (one accommodating another). A subsequent unsolved question is which mechanism produces this grain boundary shear at the microscopic scale. The earliest suggestions were diffusional processes and glide or climb of dislocations inside the boundary plane ${ }^{11}$. The existence of specific grain boundary defects has also been proposed: disconnections, i.e. line defects constrained to crystalline interfaces with both step and dislocation character ${ }^{11,15,16}$, or disclinations, i.e. rotational Volterra defects ${ }^{17-19}$. Here we undertake a detailed microstructural investigation of selected deformation experiments involving GBS to further identify the mechanisms at play.

\begin{tabular}{|c|c|c|c|c|c|}
\hline $\begin{array}{l}\text { Ref } \\
\text { sample }\end{array}$ & Apparatus & $\begin{array}{l}\text { Pressure } \\
(\mathrm{GPa})\end{array}$ & $\begin{array}{l}\text { Temperature } \\
\left({ }^{\circ} \mathrm{C}\right)\end{array}$ & $\begin{array}{l}\text { Final } \\
\text { strain } \\
(\%)\end{array}$ & $\begin{array}{l}\text { Final } \\
\text { stress } \\
(\mathrm{MPa})\end{array}$ \\
\hline $\begin{array}{l}\text { NF950- } \\
1^{20}\end{array}$ & $\begin{array}{l}\text { Paterson } \\
\text { press }\end{array}$ & 0.3 & 950 & 3.1 & 1510 \\
\hline $\begin{array}{l}\text { NF1050- } \\
1^{20}\end{array}$ & $\begin{array}{l}\text { Paterson } \\
\text { press }\end{array}$ & 0.3 & 1050 & 10.4 & 1140 \\
\hline $\begin{array}{l}\text { NF1200- } \\
1^{20}\end{array}$ & $\begin{array}{l}\text { Paterson } \\
\text { press }\end{array}$ & 0.3 & 1200 & 10.0 & 480 \\
\hline M582 ${ }^{8}$ & $\begin{array}{l}\text { Six-ram } \\
\text { press }\end{array}$ & 5 & 1000 & 30 & - \\
\hline M640 & $\begin{array}{l}\text { Six-ram } \\
\text { press }\end{array}$ & 5 & 1000 & 40 & - \\
\hline M576 & $\begin{array}{l}\text { Six-ram } \\
\text { press }\end{array}$ & 5 & 1100 & 28 & - \\
\hline M628 & $\begin{array}{l}\text { Six-ram } \\
\text { press }\end{array}$ & 5 & 1200 & 20 & - \\
\hline
\end{tabular}

Table 1: Summary of the deformation conditions of the specimens investigated in the present study. Deformation experiments are described in Bollinger et al. (2019) ${ }^{8}$, and Gasc et al. $(2019)^{20}$. For experiments performed in the six-ram press, the final strains are estimated from the displacements of the pistons and the stress is not measured.
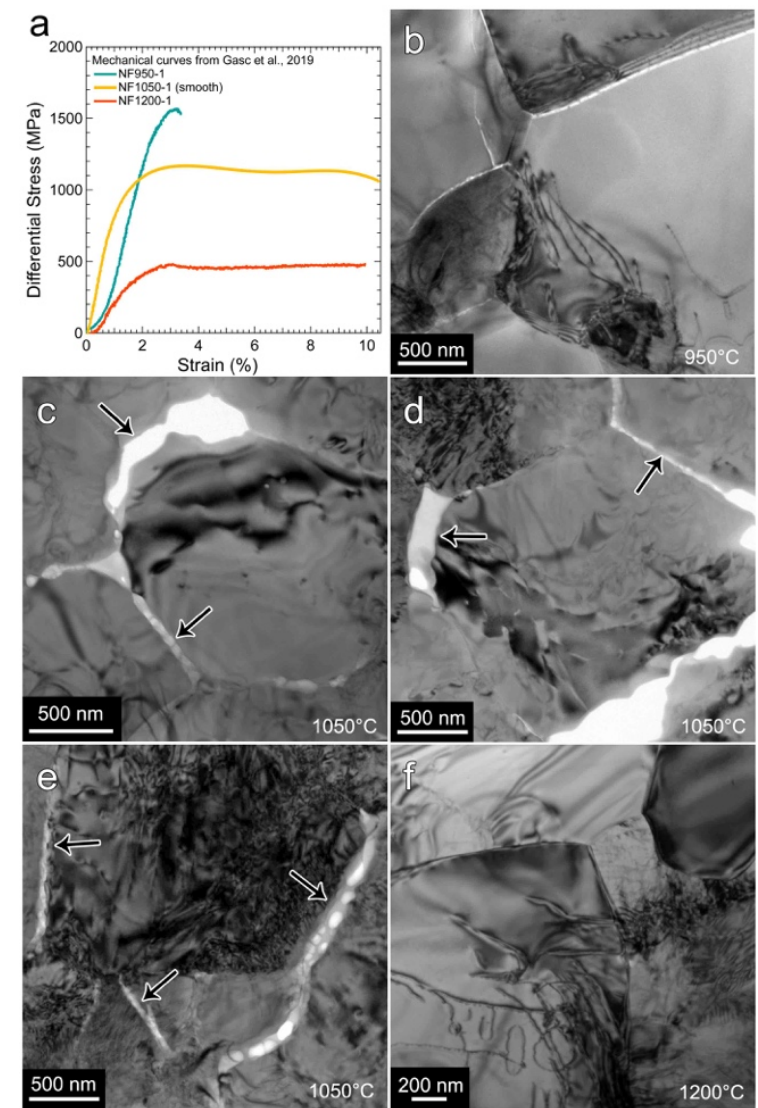

Figure 1: Specimens deformed with a Paterson press. a)

Mechanical curves in axial compression. b-f) CTEM-bright field micrographs of specimens NF950-1, NF1050-1 and NF1200-1

We investigate specimens from two previous independent studies ${ }^{8,20}$. The starting materials and experimental procedures are described in the Methods section. The deformation conditions are summarized in Table 1. We have selected three representative specimens (NF950-1, NF1050-1 and NF1200-1) out of the eight deformation experiments performed by Gasc et $a l .{ }^{20}$. They illustrate a consistent evolution with increasing temperature as shown from mechanical data and microstructures observed by conventional transmission electron microscopy (CTEM) as shown in Figure 1 (See also Extended Data Figure 1). Below 1000 ${ }^{\circ} \mathrm{C}$, the stress significantly exceeds confining pressure (> $300 \mathrm{MPa}$ ), and the samples fail after very limited plastic deformation (Figure 1a). TEM investigation shows that failure occurs predominantly at grain boundaries with some evidence of local ductile behaviour (Figure 1b). At $1200{ }^{\circ} \mathrm{C}$, ductile deformation typical of high temperature creep of olivine is observed and dislocation activity is confirmed by TEM (Figure 1f). In between these temperatures, one observes a transitional regime where stresses are still high (around $1 \mathrm{GPa}$ ) but with some ductility and where a steady-state is reached. This regime is characterized by striking microstructures showing abundant evidence for displacements across grain boundaries, either parallel 
(sliding) or perpendicular (opening, cavitation) to the boundaries (see black arrows in Figures 1c, d and e). Such microstructures have already been reported in metallic alloys (alpha iron-tin alloys ${ }^{21}, \mathrm{Ni}-\mathrm{Cr}$ alloys ${ }^{22}$, steel $^{23}$ ) and germanates ${ }^{24}$, and interpreted as evidence of GBS. At $1050{ }^{\circ} \mathrm{C}$, boundaries often show evidence of local ductility, with serration and presence of an intergranular amorphous material (see black arrows in Figure 1). Microanalysis in the TEM shows that this amorphous phase exhibits the same chemical composition as the forsterite matrix (see Extended Data Figure 2). Heterogeneous intragranular dislocation activity is also observed, but we could not find any correlation between the amount of displacement across a boundary and the local dislocation activity in neighbouring grains (Extended data Figure 3).

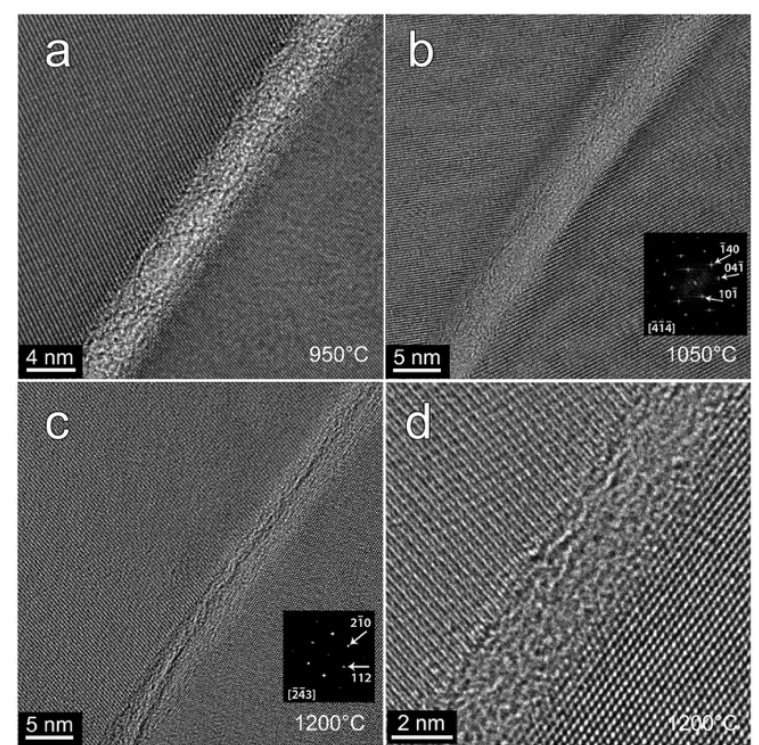

Figure 2: HRTEM of specimens deformed in the Paterson press. HRTEM micrographs of specimens a) NF950-1, b) NF1050-1 and c, d) NF1200-1. Fast Fourier Transform (FFTs) are shown in (b) and (c) confirming the olivine structure.

We have investigated the fine structure of grain boundaries using high-resolution transmission electron microscopy (HRTEM). In specimens deformed at $950^{\circ} \mathrm{C}$ and $1050^{\circ} \mathrm{C}$, many grain boundaries exhibit an intergranular amorphous layer even at a finer scale than those observed in CTEM (Figure 2a, b). The thickness of these layers varies and can be as small as a few nanometres. The most surprising observation is the presence of amorphous thin films in some grain boundaries of the specimen deformed at $1200{ }^{\circ} \mathrm{C}$ (Figures 2c and d) since this was not anticipated by the general survey of the microstructure using SEM-EBSD and CTEM. In this specimen (NF1200-1) amorphous intergranular layers are much less frequent (about ten times less) than in the other specimens.

Amorphous material is usually less dense than crystalline materials, hence amorphization might be inhibited by pressure. To verify that our observation was not specific to specimens deformed at very high stresses and crustal confining pressure, we have investigated another set of specimens deformed at $5 \mathrm{GPa}$. We have selected experiments for which GBS was established from surface microstructural characterizations ${ }^{8}$. These experiments involve another starting material (pure forsterite synthesized with a different process and with coarser grains: $20-100 \mu \mathrm{m}$ ), and a different experimental setup: a triaxial multi-anvil press. Since these experiments were not performed on a synchrotron beamline, the differential stress is unknown. The total strains are also not known with precision, but they are significantly larger $(>10 \%)$ than those reached using the Paterson press in axial compression. All specimens deformed at $5 \mathrm{GPa}$ and below $1200^{\circ} \mathrm{C}$ show pervasive amorphous grain boundaries (Figure 3). In sample M582 (deformed at $1000{ }^{\circ} \mathrm{C}$ ), we found an intergranular amorphous layer containing small features (see black arrows in Figure 3a) with Fresnel contrast suggesting the presence of nanoscale defects with local atomic density different from the surrounding amorphous material (see Methods for more details). Very similar features have already been reported in metallic glasses ${ }^{25}$ and were interpreted as nanoscale shear bands. At $1200{ }^{\circ} \mathrm{C}$ (M628, M639), some amorphous grain boundaries were found (see Figure $3 \mathrm{~d}$ with insets to confirm the crystallinity of the adjacent grains), but they were much less ubiquitous than in specimens deformed at lower temperatures (Figure 3 and Extended Data Figure 4).

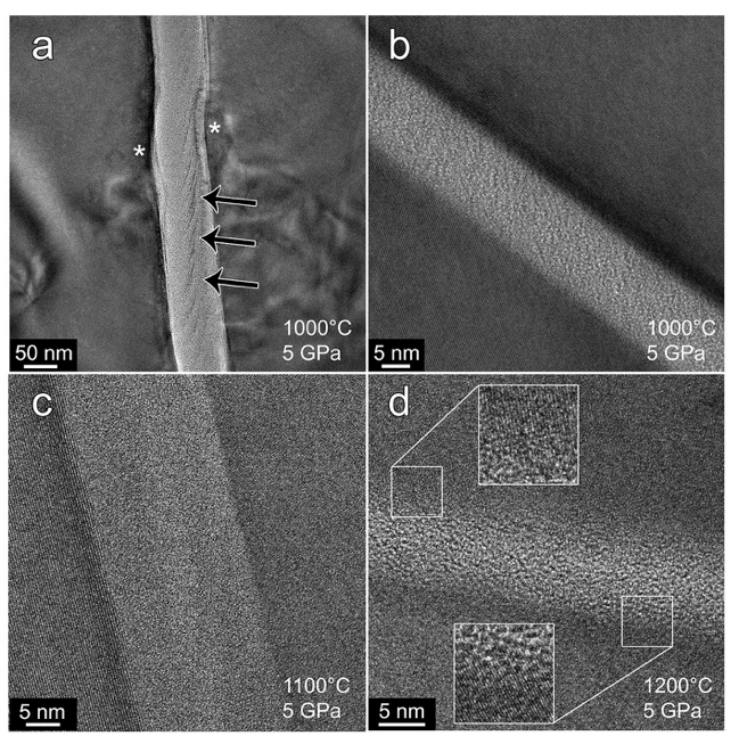

Figure 3: HRTEM of specimens deformed in the multianvil press a) $\mathrm{M} 582\left(5 \mathrm{GPa}, 1000^{\circ} \mathrm{C}\right)$, Fresnel $(\Delta \mathrm{f}=-920 \mathrm{~nm})$ micrograph. The stars highlight the displacement across the amorphous lamella, the black arrows indicate nanoscale shear bands. b) M640 (5 $\left.\left.\mathrm{GPa}, 1000^{\circ} \mathrm{C}\right) \mathrm{C}\right) \mathrm{M} 576\left(5 \mathrm{GPa}, 1100^{\circ} \mathrm{C}\right)$ and d) M628 (5 GPa, $1200^{\circ} \mathrm{C}$ ). The TEM foils in (c) and (d) were very thin compared to the other samples and very low electron dose was used leading to more noisy images (especially in (d) where magnified insets are used to show the interface between the glassy film and the lattice). 

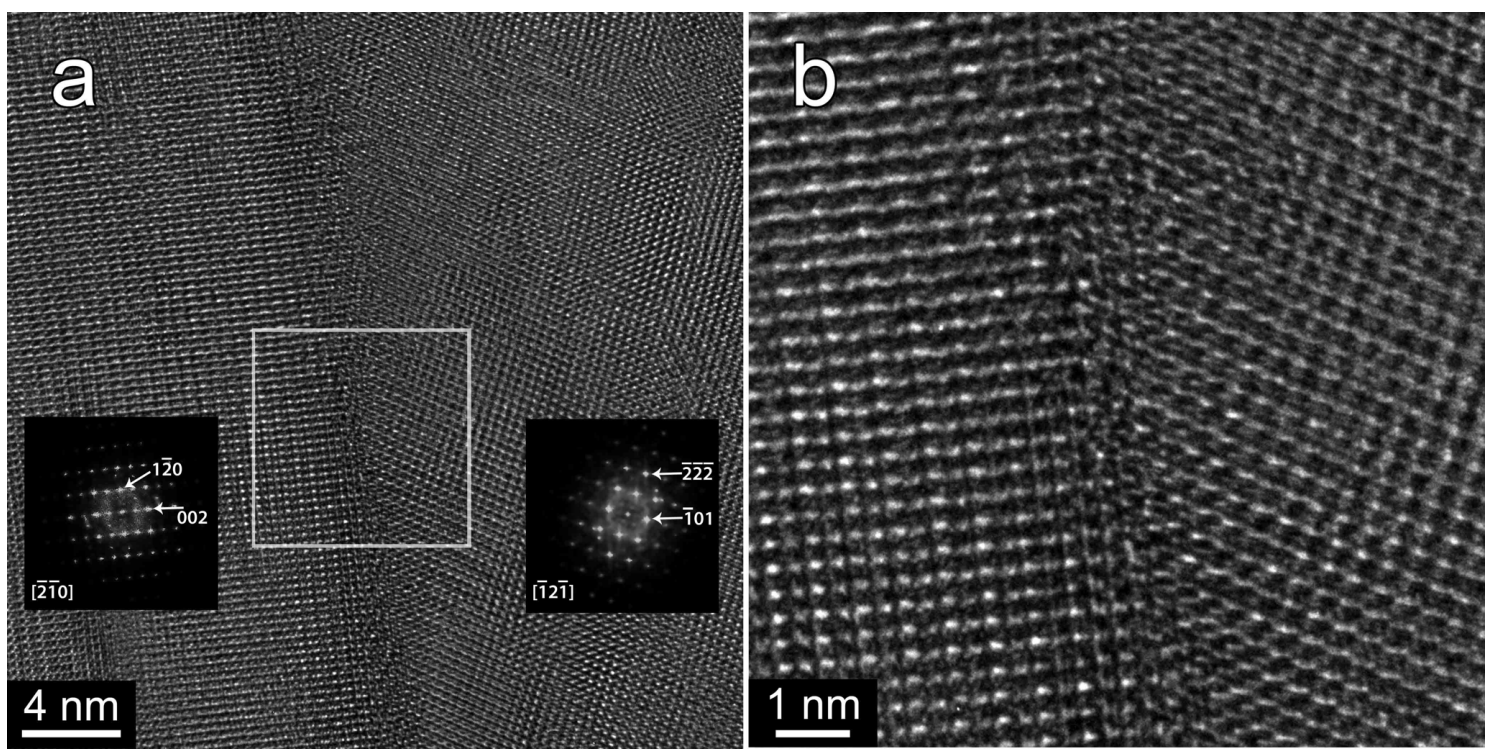

Figure 4: Starting material a) HRTEM of a grain boundary in the starting material for Paterson press experiments with FFTs from both grains and b) the enlarged image of the selected area in (a).

Intergranular amorphous layers origin. The central observation of this paper is the pervasive occurrence of amorphous layers in grain boundaries of forsterite aggregates experiencing GBS. To check that these amorphous layers are not present in the grain boundaries before deformation, we have performed an extensive characterization of the starting material prepared by Koizumi et al. (using their process described in $2010^{26}$ ). Figure 4 (see also Extended Data Figure 5) shows directly abutting lattice planes at the interface between grains with no amorphous intermediate layer.

Early studies have suggested that, at high temperature, some grain boundaries could exhibit an intergranular amorphous structure ${ }^{27}$, even before experimental evidence was shown that grain boundaries could exhibit a viscous behaviour ${ }^{28}$. Later, this hypothesis was abandoned and models involving dislocations $^{29}$, or structural units ${ }^{15}$ were preferred. However, in silicon, some high-energy grain boundaries could consist in an amorphous layer ${ }^{30}$, even at thermodynamic equilibrium. In our specimens, the amorphous layers do not result from melting nor represent a high-temperature equilibrium structure as suggested by Keblinski et al. ${ }^{30}$ since the deformation experiments performed in the Paterson press were conducted at temperatures well below the sintering temperature $\left(1260^{\circ} \mathrm{C}\right)$ or melting temperature $\left(1890^{\circ} \mathrm{C}\right)$ and the starting material shows no amorphous layer before deformation (Figure 4 and Extended Data Figure 5). Another difference is the morphology and thickness of the amorphous layers. In silicon, the hightemperature equilibrium layers are very thin (1-2 nm).
In our case, the width of the amorphized layers is very variable since it depends on the local stress-strain conditions (not on temperature) and can exceed $100 \mathrm{~nm}$ (see Figure 1d or Figure 3c).

To understand how these amorphous layers form, one must remember that olivine does not vitrify easily and that extreme cooling rates are required to form a $\mathrm{Mg}_{2} \mathrm{SiO}_{4}$ glass from molten forsterite ${ }^{31}$. However, melting followed by cooling is not the exclusive route to form amorphous materials and, in our case, melting is excluded. Olivine glass was first observed from olivine shocked experimentally at $56 \mathrm{GPa}^{32}$. Amorphous olivine can also form by static compression at room temperature in a diamond anvil cell ${ }^{33}$. In both cases, pressure is considered as the primary driving force for amorphization although the role of deviatoric stress has also been reported ${ }^{34}$. Indeed, no solid can be stressed indefinitely without undergoing some fundamental mechanical instability resulting in crystal structure collapse. In a perfect solid loaded under a uniform deformation, the corresponding stress is called the ideal shear or tensile stress, depending upon the loading mode. In forsterite, this instability threshold can be as low as $6 \mathrm{GPa}$ at $0 \mathrm{~K}^{35}$ (when shear is applied on (100)). This is consistent with the recent observation of amorphous shear bands in single crystal olivine micropillars compressed at ca. $4 \mathrm{GPa}^{36}$. For olivine, there is no theoretical prediction on the influence of defective regions like grain boundaries on the instability threshold. In alumina, a $\Sigma 13$ [1 $\overline{2} 10]$ pyramidal twin GB exhibits a strength reduction greater than $60 \% \%^{37}$ compared to perfect alumina ${ }^{38}$. In an anisotropic crystal 
as olivine, grain boundaries are loci of stress concentrations and below $1000{ }^{\circ} \mathrm{C}$, applied stresses are in the GPa range. Hence, we consider that preferential, stress-induced amorphization at grain boundaries by mechanical instability represents a reasonable framework to interpret our observations. The fact that those amorphous layers are also observed in specimens deformed using a multi-anvil press demonstrates that amorphization of grain boundaries is not inhibited by a confining pressure up to $5 \mathrm{GPa}$.

Amorphization promotes GBS. We propose that, in olivine aggregates deformed under local high stress, grain boundaries amorphize and promote GBS. This mechanism has been demonstrated recently in 'superhard' $\mathrm{B}_{4} \mathrm{C}$ ceramic ${ }^{39}$. It may be common to several hard materials loaded under high stress conditions.

Amorphous grain boundaries change our appreciation of the rheology of olivine-rich rocks. Contrary to a crystal, an amorphous material is characterized by the glass transition which is a marked change of behaviour from a hard and relatively brittle state to a viscous state as the temperature is increased. The experiments at $0.3 \mathrm{GPa}^{20}$ show that the change of rheology of the grain boundaries occurs in the temperature range $1000-1100{ }^{\circ} \mathrm{C}$. Below this temperature interval, the specimens are mostly brittle, while they are ductile above (i.e. at $1200{ }^{\circ} \mathrm{C}$ ) with a regular dislocation creep behaviour. In the multi-anvil experiments $^{8}$, the change of deformation regime is found in the same temperature range from the analysis of local misorientation heterogeneities (see Figure 9 in ref. 8). This behaviour is supported by our observations. At $950{ }^{\circ} \mathrm{C}$, grain boundaries amorphize but brittle intergranular failure is observed with very little flow (see Figure $1 \mathrm{~b}$ and Extended Data Figure 7). In specimens deformed in the multi-anvil apparatus we observe shear bands (Figure $3 \mathrm{a}$ and Extended Data Figure 9) in specimens deformed at $1000{ }^{\circ} \mathrm{C}, 5 \mathrm{GPa}$, that are a strong indication of a shear component of deformation within the amorphous layer, below the glass transition temperature $\left(T_{g}\right)$ since inhomogeneous flow is characteristic of deformation in the glassy state ${ }^{40}$. Above $1000^{\circ} \mathrm{C}$, we observe pervasive evidence of ductile flow at grain boundaries (see Figures 1c, $d$ and e and Extended Data Figure 8). In the specimens deformed in the Paterson press, where the confining pressure is low compared to the deviatoric stress, several grain boundaries are under tensile conditions leading to grain separations involving extensive flow and cavitation in the amorphous intragranular layer (see evaluation of the strain produced in the Methods section). The glass transition temperature, $T_{g}$, of forsterite $^{31}, 1263 \pm 10{ }^{\circ} \mathrm{C}$, is very consistent with our observations (see further discussion in the Methods section) and accounts well for the rheology contrast observed in the mechanical data.
Implications on deep Earth processes. Under lithospheric stresses (several hundreds of $\mathrm{MPa}^{41-42}$ ), local stress concentrations at grains boundaries can approach a GPa level ${ }^{43}$ necessary to lead to solid-state amorphization of olivine. Such high stress conditions might be relevant to explain the brittle-plastic transition observed around the $600{ }^{\circ} \mathrm{C}$ isotherm in the oceanic lithosphere ${ }^{44,45}$, as well as within the cold corner of the mantle wedge in subduction zones ${ }^{46}$. However, the corresponding temperatures are rather low and grain boundary amorphization might only trigger a limited, hence transient, ductility ${ }^{47}$. Considering the specific rheological properties of glasses described above, a major rheological transition is more expected when olivine-rich rocks with such amorphized grain boundaries reach the glass transition temperature. This leads us to propose a new origin for the viscosity drop at the lithosphere-asthenosphere boundary (LAB) which remains elusive and largely debated.

With increasing depths, the transition between the rigid lithosphere and the underlying convecting asthenosphere (as enunciated by Barrell ${ }^{48}$ ) takes place without major mineralogical and compositional changes in mantle rocks ${ }^{49}$. To date a clear agreement has not been reached and several thermomechanical hypotheses are debated:

(1) a layer with high homologous temperature (relative to melting temperature $\mathrm{T}_{\mathrm{m}}$, but below solidus) would be enough to drastically impact the mechanisms of plastic deformation of olivine-rich aggregates ${ }^{50}$;

(2) the presence of a melt-rich layer at the $\mathrm{LAB}^{51-}$ 53 , enhanced by incorporation of volatiles in mantle rocks such as $\mathrm{CO}_{2}$ in the asthenosphere ${ }^{54}$ or by the fast destabilization and dehydration of the mineral pargasite $^{55}$.

(3) by a change in dislocation activity in olivine as a function of temperature and pressure. Laboratory experiments reported that dislocation glide in olivine crystals switches from $[100](0 \mathrm{kl})$ to $[001](\mathrm{hk} 0)$ below $1000{ }^{\circ} \mathrm{C}^{56}$ while an increase in pressure would induce the opposite effect ${ }^{57,58}$. Such a slip system switch could potentially lead to a notable change of viscosity. Nevertheless, the magnitude of this effect is difficult to assess as experimental data need to be extrapolated to asthenospheric strain rates $\left(10^{-14}-10^{-18} \mathrm{~s}^{-1}\right)$ and low stresses $(<50 \mathrm{MPa})$. Also, mantle-derived peridotites are only available from the lithosphere and cannot help constraining a full lithosphere-asthenosphere textural transition. The current database only reports abundant $[100](0 \mathrm{kl})$ textures in peridotites for the lithosphere ${ }^{59}$.

The only consensus, derived from large scale numerical models, is the satisfying match of the viscosity drop at the $\mathrm{LAB}$ with a layer at $1027-1127^{\circ} \mathrm{C}$ $(1300-1400 \mathrm{~K})$ isotherms ${ }^{60-62}$. Assuming that the origin of the LAB is linked to the rheology of olivine-rich 
rocks, our results suggests a different mechanism which is controlled by the onset of ductility at amorphized grain boundaries. Once the glass transition temperature of olivine glass is reached, amorphized grain boundary flow, enhancing sliding and leading to a marked viscosity drop of the mantle rocks. The consistency between the isotherm defining the LAB and the glass transition temperature of olivine glass supports our model. Our results infer a change of paradigm since until now the rheology of rocks was considered to be exclusively dependent on the physics of crystal defects whereas we should draw our attention to the mechanical properties of olivine glass. At greater depths, in the asthenosphere, i.e. after the viscosity drop, the stresses $(<10 \mathrm{MPa})$ are too low to trigger amorphization of grain boundaries. Since temperatures are also higher than in the lithosphere, one can expect that, in the asthenosphere, other mechanisms operate at the grain boundaries involving either ionic diffusion or activation of specific defects (disconnections, disclinations). Dedicated experiments and modelling are needed to define more precisely the thermomechanical fields of activation of these different mechanisms.

\section{References}

1. Carter, N.L., Ave'Lallemant, H.G. High Temperature flow of dunite and peridotite. Geol. Soc. America. Bull. 81, 2181-2202 (1970).

2. Kocks, U.F., Argon, A.S. and Ashby, M.F. 4. Thermal activation. In: U.F. Kocks, A.S. Argon and M.F. Ashby (Editors), Thermodynamics and kinetics of slip, Pergamon Press, pp. 110-271 (1975).

3. Ashby, M.F. and Verrall, R.A. Micromechanisms of flow and fracture, and their relevance to the rheology of the upper mantle. Phil. Trans. R. Soc. Lond. A. 288, 59-95 (1977).

4. Marquardt, K. \& Faul, U.K. The structure and composition of olivine grain boundaries: 40 years of studies, status and current developments. Phys Chem Minerals, 45, 139-172 (2018). https://doi.org/10.1007/s00269-017-0935-9

5. Hirth, G. \& Kohlstedt, D.L. Experimental constraints on the dynamics of the partially molten upper mantle: 2. Deformation in the dislocation creep regime, J. Geophys. Res. 100, 15441-15449 (1995)

6. Warren, J. M. \& Hirth, G. Grain size sensitive deformation mechanisms in naturally deformed peridotites, Earth Planet. Sci. Lett., 248(1-2), 438450 (2006) doi:10.1016/j.epsl.2006.06.006.

7. Maruyama, G. \& Hiraga, T. Grain- to multiplegrain-scale deformation processes during diffusion creep of forsterite + diopside aggregate: 1. Direct observations. J. Geophys. Res. Solid Earth 122, 5890-5915 (2017) doi:10.1002/2017JB014254.

8. Bollinger C., Marquardt, K., \& Ferreira F. Intragranular plasticity vs. grain boundary sliding (GBS) in forsterite: microstructural evidence at high pressures (3.5-5.0 GPa). Am. Mineral. 104 (2), 220$231(2019)$
9. Ohuchi, T., Kawazoe, T., Higo, Y., Funakoshi, K.i., Suzuki, A., Kikegawa, T., \& Irifune, T. Dislocation-accommodated grain boundary sliding as the major deformation mechanism of olivine in the Earth's upper mantle. Sci. Adv. 1, e1500360 (2015).

10. Burnley, P.C. \& Kaboli, S. Elastic plastic selfconsistent (EPSC) modeling of San Carlos olivine deformed in a D-DIA apparatus. Am. Mineral. 104, 276-281 (2019)

11. Ashby, M. F. Boundary defects and atomistic aspects of boundary sliding and diffusional creep. Surf. Sci. 31, 498-542. (1972) doi:10.1016/00396028(72)90273-7

12. Raj, R., \& Ashby, M. F. On grain boundary sliding and diffusional creep, Metall. Trans., 2, 1113- 1127 (1971)

13. Cooper, R.F. Seismic Wave Attenuation: Energy Dissipation in Viscoelastic Crystalline Solids. In: Plastic Deformation of Minerals and Rocks; Reviews in Mineralogy and Geochemistry, Publisher: Mineralogical Society of America. Editors: S.-i. Karato and H.-R. Wenk. 51(9), 253290 (2002)

14. Jackson, I, Faul, U \& Skelton, R. Elastically accommodated grain-boundary sliding: New insights from experiment and modeling, Phys. Earth Planet. Int. 228, 203-210 (2014)

15. Bollmann, W. Crystal defects and Crystalline Interfaces (Springer, Berlin, Germany) (1970)

16. Hirth, J.P., Hirth, G. \& Wang, J., Disclinations and disconnections in minerals and metals Proc. Nat. Acad. Sci. 117, 196-204 (2020) doi: 10.1073/pnas. 1915140117

17. Volterra, V. Sur l'équilibre des corps élastiques multiplement connexes. Ann. Sci. Ecol. Norm. Sup. III 24, 401-517, (1907)

18. Taupin, V., Capolungo, L., Fressengeas, C., Das, A., \& Upadhyay, M., Grain boundary modeling using an elasto-plastic theory of dislocation and disclination fields. J. Mech. Phys. Solids 61 (2), 370384 (2013).

19. Cordier, P., Demouchy, S., Beausir, B., Taupin, V., Barou, F. \& Fressengeas C. Disclinations provide the missing mechanism for deforming olivine-rich rocks in the mantle. Nature, 507, 51-56, (2014) doi : 10.1038/nature13043

20. Gasc, J., Demouchy, S., Barou, F., Koizumi, S. \& Cordier, P. Creep mechanisms in the lithospheric mantle Inferred from deformation of iron-free forsterite aggregates at $900-1200{ }^{\circ} \mathrm{C}$. Tectonophysics, 761, 16-30, (2019) https://doi.org/10.1016/j.tecto.2019.04.009

21. Watanabe, T., Obata, M., \& Karashima, S. High Temperature Intergranular Fracture Enhanced by Grain Boundary Migration in Alpha Iron-Tin Alloy. Strength of Metals and Alloys (ICSMA 6). Proceedings of the $6^{\text {th }}$ International Conference, Melbourne, Australia, 671-676 (1982)

22. Schneibel, J.H., White, C.L. \& Padgett, R.A. The Influence of Traces of $\mathrm{Sb}$ and $\mathrm{Zr}$ on Creep and Creep Fracture of $\mathrm{Ni}-20 \%$ Cr. Strength of Metals and Alloys (ICSMA 6) Proceedings of the $6^{\text {th }}$ 
International Conference, Melbourne, Australia, 649-654 (1982)

23. Masuda, H., Tobe, H., Sato, E., Sugino, Y. \& Ukai, S. Two-dimensional grain boundary sliding and mantle dislocation accommodation in ODS ferritic steel. Acta Mater. 120, 205e215 (2016)

24. Dupas-Bruzek, C., Tingle, T., Green II, H., Doukhan, N., \& Doukhan, J.C. The rheology of olivine and spinel magnesium germanate $\left(\mathrm{Mg}_{2} \mathrm{GeO}_{4}\right)$ : TEM study of the defect microstructures. Phys. Chem. Minerals, 25( 7), 508509 (1998)

25. Rösner, H., Peterlechner, M., Kübel, C., Schmidt, V., and Wilde, G. Density changes in shear bands of a metallic glass determined by correlative analytical transmission electron microscopy. Ultramicroscopy, $\quad 142, \quad 1-9 \quad$ (2014) https://doi.org/10.1016/j.ultramic.2014.03.006

26. Koizumi, S., Hiraga, T., Tachibana, C., Tasaka, M., Miyazaki, T., Kobayashi, T., Takamasa, A., Ohashi, N., \& Sano, S. Synthesis of highly dense and finegrained aggregates of mantle composites by vacuum sintering of nano-sized mineral powders. Phys. Chem. Minerals 37, 505-518. (2010)

27. Rosenhain, W. \& Ewen, D. Intercrystalline cohesion in metals. J. Inst. Metals 8, 149-173 (1912).

28. Ke, T.S. Experimental Evidence of the Viscous Behavior of Grain Boundaries in Metals. Phys. Rev, 71(8), 533-546 (1947)

29. Read, W.T. \& Shockley, W. Dislocation models of crystal grain boundaries. Phys. Rev. 78, 275-289 (1950)

30. Keblinski, P., Wolf, D., Phillpot, S. R. \& Gleiter, H. Thermodynamic Criterion for the Stability of Amorphous Intergranular Films in Covalent Materials Phys. Rev. Lett. 77, 2965-2968 (1996).

31. Richet, P., Leclerc, F. \& Benoist, L. Melting of forsterite and spinel, with implications for the glass transition of $\mathrm{Mg}_{2} \mathrm{SiO}_{4}$ liquid, Geophys. Res. Lett, 20, 1675-1678 (1993)

32. Jeanloz, R., Ahrens, T.J., Lally, J.S., Nord, G.L., Christie, J.M. \& Heuer, A.H. Shock-Produced Olivine Glass: First Observation. Science, 197( 4302), 457-459 (1977)

33. Lacam, A., Madon, M. \& Poirier, J.P. Olivine glass and spinel formed in a diamond anvil high-pressure cell. Nature, 288, 155-157 (1980)

34. Andrault, D., Bouhifd, M.A., Itie, J.P., \& Richet, P. Compression and amorphization of $(\mathrm{Mg}, \mathrm{Fe})_{2} \mathrm{SiO}_{4}$ olivines: An X-ray diffraction study up to $70 \mathrm{GPa}$. Phys. Chem. Minerals, 22, 99-107 (1995)

35. Gouriet, K., Carrez, P. \& Cordier, P. Ultimate mechanical properties of forsterite. Minerals, 9, 787 (2019) http://dx.doi.org/10.3390/min9120787

36. Kranjc, K., Thind, A.S., Borisevich, A.Y., Mishra, R., Flores, K.M. \& Skemer, P. Amorphisation and plasticity of olivine during low temperature micropillar deformation experiments. J. Geophys. Res. Solid Earth 125, e2019JB019242. https://doi.org/10.1029/2019JB019242

37. Nakamura, K., Mizoguchi, T., Shibata, N., Matsunaga, K., Yamamoto, T. \& Ikuhara, Y. Firstprinciples study of grain boundary sliding in $\alpha$ $\mathrm{Al}_{2} \mathrm{O}_{3}$. Phys. Rev. B 75, 184109 (2007)
38. Zhang, Z., Fu, Z., Zhang, R., Legut, D. \& Guo, H. Anomalous mechanical strengths and shear deformation paths of $\mathrm{Al}_{2} \mathrm{O}_{3}$ polymorphs with high iconicity. RSC Advances. 6(16), 12885 (2016) doi: 10.1039/C5RA25796D

39. Guo, D., Song, S. Luo, R., Goddard III. W.A., Chen, M., Reddy, K.M. \& An, Q. Grain boundary sliding and amorphization are responsible for the reverse Hall-Petch relation in superhard nanocrystalline boron carbide. Phys. Rev. Lett., 121, 145504, (2018) doi:10.1103/PhysRevLett.121.145504

40. Schuh, C.A., Hufnagel, T.C. \& Ramamurty, U. Mechanical behavior of amorphous alloys. Acta Mater. $\quad 55, \quad 4067-4109 \quad$ (2007) doi:10.1016/j.actamat.2007.01.052

41. Zoback, M.L., \& Zoback, M. Lithosphere stress and deformation. Treatise on Geophysics. 6, 253-273 (2007) https://doi.org/10.1016/B978-0444527486.00105-X

42. Boioli, F., Tommasi, A., Cordier, P., Demouchy, S. \& Mussi, A. Low steady-state stresses in the cold lithospheric mantle inferred from dislocation dynamics models of dislocation creep in olivine. Earth Planet. Sci. Lett.432, 232-242 (2015) http://dx.doi.org/10.1016/j.epsl.2015.10.012

43. Wallis, D., Hansen, L.N., Britton, T.B., Wilkinson, A.J. High-Angular Resolution Electron Backscatter Diffraction as a New Tool for Mapping Lattice Distortion in Geological Minerals. J. Geophys. Res. Solid Earth 124, 6337-6358.( 2019) doi:10.1029/2019JB017867

44. McKenzie, D., Jackson, J., Priestley, K. Thermal structure of oceanic and continental lithosphere. Earth Planet. Sci. Lett. 233, 337-349 (2005) doi:10.1016/j.epsl.2005.02.005

45. Watts, A.B., Zhong, S. Observations of flexure and the rheology of oceanic lithosphere. Geophys. J. Int. $142,855-875$ (2000)

46. Kneller, E.A., van Keken, P.E., Karato, S.-I, Park, J. B-type olivine fabric in the mantle wedge: Insights from high-resolution non-Newtonian subduction zone models. Earth Planet. Sci. Lett. 237, 781-797 (2005) doi:10.1016/j.epsl.2005.06.049

47. Pollitz, F.F. Lithosphere and shallow asthenosphere rheology from observations of post-earthquake relaxation. Phys. Earth Planet. Int. 293, 106271 (2019) doi: 10.1016/j.pepi.2019.106271

48. Barrell, J. The strength of the Earth's crust. $J$. Geology 14, 28-48 (1914)

49. O'Reilly, S.Y., Griffin, W.L. The continental lithosphere-asthenosphere boundary: Can we sample it? Lithos 120, 1-13. (2010) doi:10.1016/j.lithos.2010.03.016

50. Wang, Q. Homologous temperature of olivine: Implications for creep of the upper mantle and fabric transitions in olivine. Sci. China Earth Sci. 59, 1138-1156 (2016) doi:10.1007/s11430-016-5310-z

51. Sakamaki, T. Ponded melt at the boundary between the lithosphere and asthenosphere Nature Geoscience. 6, 1041-1044 (2013) doi:10.1038/ngeo1987

52. Kawakatsu, H., Kumar, P., Takei, Y., Shinohara, M., Kanazawa, T., Araki, E., Suyehiro, K., 2009. Seismic Evidence for Sharp Lithosphere- 
Asthenosphere Boundaries of Oceanic Plate, Science, 324, 499-502 (2009)

53. Naif, S., Key, K., Constable, S., Evans, R.L. Meltrich channel observed at the lithosphereasthenosphere boundary. Nature 495, 356-359 (2013) doi:10.1038/nature11939

54. Gaillard, F., Malki, M., Iacono-Marziano, G., Pichavant, M., Scaillet, B. Carbonatite melts and electrical conductivity in the asthenosphere. Science, 322, 1363-1365 (2008)

55. Green, D.H., Hibberson, W.O., Kovács, I., Rosenthal, A. Water and its influence on the lithosphere- asthenosphere boundary. Nature 467, 448-451 (2010) doi:10.1038/nature09369

56. Raleigh, C.B. Mechanism of plastic deformation of olivine. J. Geophys. Res. 73, 5391-5406 (1968)

57. Couvy, H., Frost, D. J., Heidelbach, F., Nyilas, K., Ungár, T., Mackwell, S., \& Cordier, P. Shear deformation experiments of forsterite at $11 \mathrm{GPa}$ $1400{ }^{\circ} \mathrm{C}$ in the multianvil apparatus. Eur. J. Mineral. 16 (6), 877-889 (2004)

58. Mainprice, D., Tommasi, A., Couvy, H., Cordier, P., \& Frost, D.J. Pressure sensitivity of olivine slip systems and seismic anisotropy of Earth's upper mantle. Nature 433, 731-733 (2005)

59. Ben Ismail, W. \& Mainprice, D. An olivine fabric database: an overview of upper mantle fabrics and seismic anisotropy. Tectonophysics 296, 145-157 (1998)

60. Pollack, H.N., \& Chapman, D.S. On the regional variation of heat flow, geotherms, and lithospheric thickness. Tectonophysics. 38, 279-296 (1977).

61. Eaton, D.W., Darbyshire, F., Evans, R.L., Grütter, H., Jones, A.G., Yuan, X. The elusive lithosphereasthenosphere boundary (LAB) beneath cratons. Lithos 109, 1-22. doi:10.1016/j.lithos.2008.05.009

62. Fischer, K.M., Ford, H.A., Abt, D.L. \& Rychert, C.A.. The Lithosphere-Asthenosphere Boundary. Annu. Rev. Earth Planet. Sci. 38, 551-575 (2010) doi:10.1146/annurev-earth-040809-152438

Aknowledgements We acknowledge funding from the European Research Council (ERC) under the European Union's Horizon 2020 research and innovation programme under grant agreement No 787198 - TimeMan. The TEM facility in Lille (France) is supported by the Conseil Régional du Nord-Pas de Calais, and the European Regional Development Fund (ERDF). H. Idrissi is mandated by the Belgian National Fund for Scientific Research (FSR-FNRS). This study was also partially supported by the Agence Nationale de la Recherche through the ANR INDIGO grant (ANR-14-CE33-0011) for the low-pressure experiments, by the German Alexander von Humboldt Foundation and the Free State of Bavaria for the highpressure experiments, and by the JSPS KAKENHI grant (number JP18K03799) to Sanae Koizumi and cooperative research program of the Earthquake Research Institute, Tokyo (Japan).

Author contribution The study was designed by P.C. and cosupervised by P.C. and H.I. S.K. prepared the starting material nanoforsterite. C.B. prepared the coarse-grained forsterite. J.G., S.D. and C.B. performed the deformation experiments. V.S., H.I., A.M., D.S. and P.C. performed and analysed the TEM investigations. All the authors discussed and analysed the data. P.C., H. I. and S.D. wrote the paper with contribution of all authors.

The authors declare no competing interests.

\section{Online methods section:}

\section{Deformation of forsterite fine-grained aggregates in the Paterson press ${ }^{20}$}

Starting material: forsterite and enstatite nanosized powders were synthesized from colloidal $\mathrm{SiO}_{2}$ (average particle size: $30 \mathrm{~nm}$, purity: 99.9\%) and $\mathrm{Mg}(\mathrm{OH})$ (average particle size: $50 \mathrm{~nm}$, purity: 99.98\%) at the Earthquake Research Institute (Tokyo, Japan), following the sintering method detailed in Koizumi et $a l^{26}$. After cold-pressing the nano-powder mixture was annealed under vacuum at $1260{ }^{\circ} \mathrm{C}$ for $2-3$ hours. This yields a very dense polycrystalline solid with porosity well below 1\% and melt-free grain boundaries (Fig. 1). This type of high-quality sintered polycrystal is now a standard for deformation studies $7,63,64$. The average grain size is $2.8 \mu \mathrm{m}$ and the aggregate contains between 2 and $3 \%$ of orthoenstatite grains (grain size $1.8 \mu \mathrm{m}$ ), which are homogeneously distributed. Orthoenstatite is not stable under $300 \mathrm{MPa}$ above $1000{ }^{\circ} \mathrm{C}$ and transforms into proto-enstatite, but the mineral remains far from its melting point $\left(1550-1600{ }^{\circ} \mathrm{C}^{65,66}\right)$. The EBSD maps of the starting material shows equilibrated textures, with ubiquitous triple junctions and straight grain boundaries $^{20,26}$. Cylinders of nano forsterite+enstatite were then cut, polished and reshaped as cylinders for the deformation experiments.

Deformation experiments: experiments NF9501, NF1050-1 and NF1200-1 from Gasc et al. ${ }^{20}$ were carried out using a Paterson press at Geosciences Montpellier (University of Montpellier, France), which is a servo-controlled high-resolution gas-medium (argon) high-pressure high-temperature deformation apparatus ${ }^{67,68}$. Deformation experiments were performed under a confining pressure of $300 \pm 5 \mathrm{MPa}$, at temperatures between 900 and $1200{ }^{\circ} \mathrm{C}$, and at a constant displacement rate. The assembly is rather standard: the samples were placed between $\mathrm{Al}_{2} \mathrm{O}_{3}$ and $\mathrm{Mg}$-doped $\mathrm{Zr}_{2} \mathrm{O}_{3}$ pistons and surrounded with soft metal sleeves $^{50}$. The nature of the soft metal sleeve is a function of the temperature of each experiment (i.e., silver, copper and nickel sleeves were used for experiments at $<1000^{\circ} \mathrm{C}, 1000-1050{ }^{\circ} \mathrm{C}$, and $>1050{ }^{\circ} \mathrm{C}$, respectively). The constant displacement rate was set based on the initial length of the polycrystalline cylinder to yield a constant strain rate of $10^{-5} \mathrm{~s}^{-1}$. Steady-state was not reached for every deformation experiments and finite strain ranged from 3.1 to $10.3 \%$ (Table 1 ). The furnace was pre-calibrated for each targeted temperature and was monitored with a commercial N-type thermocouple (Nicrosil-Nisil). The temperature gradients along the hot zone $(2 \mathrm{~cm})$ did not vary by more than $5^{\circ} \mathrm{C}$. Isostatic quenching of the samples is achieved by a manual decrease of the furnace power, at a rate of $100{ }^{\circ} \mathrm{C} / \mathrm{min}$ down to $400^{\circ} \mathrm{C}$ and then at $40^{\circ} \mathrm{C} / \mathrm{min}$ down to $150{ }^{\circ} \mathrm{C}$, which is fast enough to limit relaxation and to ensure preservation of the deformation microstructures ${ }^{69}$. The decrease in temperature induces 
a decrease in confining pressure (typically $65 \mathrm{MPa}$ as the gas condensed) as well as in applied stress before the load is completely removed. In average, quench takes 14 to 16 minutes, which yields a characteristic distance of $\mathrm{Si}$ diffusion in forsterite $\sim 0.6 \mathrm{~nm}$ for a typical decrease in temperature (NB: using the self-diffusion of Si in pure forsterite $^{70}$ ).

\section{Deformation of forsterite aggregates in the multi-anvil press ${ }^{8}$}

Starting material: forsterite was synthesized from $\mathrm{MgO}(99.99 \%$ purity with $1.5 \mu \mathrm{m}$ grain size) and $\mathrm{SiO}_{2}(99.99 \%$ purity with $\sim 150 \mu \mathrm{m}$ grain size) oxide powders from ChemPur. The powders were mixed together in an alumina mortar with ethanol. $\mathrm{MgO}$ was added in excess to avoid the formation of enstatite during synthesis since $\mathrm{MgO}$ powders easily captures humidity from the air during weighing. This mixture was then sintered in a furnace at $1500^{\circ} \mathrm{C}$ for at least 12 $\mathrm{h}$ and ground again. This procedure was repeated until the evolution to $100 \%$ forsterite was demonstrated with $\mathrm{X}$-ray diffraction. Then, the $\mathrm{MgO}$ in excess was removed using $10 \%$ acetic acid at $60{ }^{\circ} \mathrm{C}$. The resulting forsterite powder was then sent to PNF2 (CIRIMAT, Toulouse, France) to be aggregated and densified by flash sintering ${ }^{71}$. This resulted in pellets $2 \mathrm{~cm}$ of thick and $4 \mathrm{~cm}$ in diameter. The starting microstructure of the aggregate has been analysed with a Scanning Electron Microscope (SEM) and EBSD before deformation. The grain size was between 20 and $100 \mu \mathrm{m}$ with a lognormal distribution. The grains are randomly orientated with straight grain boundaries.

Deformation experiments: experiments M576, M582, M628 and M640 from Bollinger et al. ${ }^{8}$ were carried out using a six-ram MAVO press ${ }^{72}$ at the Bayerisches Geoinstitut (Bayreuth, Germany). The specimens are inserted in a molybdenum capsule and placed between alumina pistons. The assemblies containing a graphite furnace are placed between the six second-stage anvils. The pressurization is followed by power-controlled heating. After reaching the desired $\mathrm{P} / \mathrm{T}$ conditions, annealing was performed for $\sim 30 \mathrm{~min}$ before deformation is achieved by pushing one pair of rams forward by injecting oil at a rate corresponding to an applied strain rate of $\sim 2 \times 10^{-5} \mathrm{~s}^{-1}$. Another pair of rams remains fixed as the last one was pushed backward in response to maintain a constant confining pressure while the sample was deformed in pure shear geometry. In this experiment stress is not measured. The final strain (Table 1) is estimated from the displacements of the ram. After deformation, the specimen is quenched under pressure to ca. $100^{\circ} \mathrm{C}$ in a few seconds by turning off the power to the furnace. Quench rates are fast due to the small size of the pressure cell and the large volume of metal around it.

\section{Transmission electron microscopy}

The specimens were first mechanically polished down to a thickness of $30 \mu \mathrm{m}$. In order to reach electron transparency, the sample foils mounted on $\mathrm{Mo}$ or $\mathrm{Cu}$ grids were Ar-ion sputtered with a Gatan ${ }^{\circledR}$ DuoMill $^{\mathrm{TM}}$ model 600. In case of specimens deformed in the multianvil press, a final polishing was performed during a few minutes at grazing angle with a Gatan ${ }^{\circledR}$ PIPS $^{\text {TM }}$ II model 695. A thin carbon layer has been deposited to ensure electron conduction on the thin-foils. CTEM as well as STEM-EDX observations were carried out in Lille using a FEI ${ }^{\circledR}$ Tecnai $\mathrm{G}^{2}-20$ twin microscope operating at $200 \mathrm{kV}$ equipped with a $\mathrm{LaB}_{6}$ filament and using a double tilt sample-holder. HRTEM micrographs were acquired in Antwerp using an aberration-corrected cubed FEI-Titan electron microscope at an operating voltage of $300 \mathrm{kV}$. Fresnel contrast was used to increase the contrast of the small shear bands in Figure 3a. This technique is commonly used in TEM to reveal regions with different atomic density, bubbles or voids in solids by acquiring overfocused and underfocused images. Such behaviour is very useful here because shear bands exhibits slight changes of atomic density (from $1 \%$ to $10 \%$ ) between sheared zones and the surrounding amorphous matrix ${ }^{25}$.

\section{Local strain measurements}

The strain produced by grain boundary sliding can be measured from the transverse displacement $u$ across the boundary from the expression ${ }^{73}$ :

$$
\varepsilon_{G B S}=\phi \frac{u}{L}
$$

Where $\phi$ is a geometrical constant close to $1.5^{74}$ and $L$ is the (average) grain size.

In Figure 1d or Extended Data Figure 8b, the amorphous layer formed between two grains which are pulled apart (horizontal displacement on the picture). In Extended Data Figure $8 \mathrm{~b}$ the amorphous boundary is $190 \mathrm{~nm}$ wide. Since an amorphous silicate is ca. $20 \%$ less dense than the crystalline form, the formation of this layer corresponds to a displacement of $12 \mathrm{~nm}(\Delta V / V \approx$ 3. $\Delta l / l)$ which corresponds to a $0.6 \%$ local strain (considering the size of the grain on the right).

The contribution of shear to sliding is more difficult to demonstrate if no markers are available. One occurrence is illustrated in Figure $3 \mathrm{a}$ on the M582 specimen deformed at $5 \mathrm{GPa}, 1000{ }^{\circ} \mathrm{C}$. Shear deformation is evidenced by two markers. One is the observation of nanoscale shear bands. The second one is given by the displacements of the two crystalamorphous boundaries highlighted by the white asterisks. These two independent markers give a consistent value of ca. $50 \mathrm{~nm}$ for the shear component. Considering that in this specimen, the grain size is in the range $20-100 \mu \mathrm{m}$, one can bracket the shear component of the strain produced at this grain boundary: $0.075 \%<$ $\varepsilon_{G B S}<0.375 \%$. The tensile component of strain across 
the boundary is approximately three times smaller. The smallness of this value is related to the magnification which can only capture small displacements. However, given the grain size and the size of the specimen, such a contribution supposed to be spread homogeneously among all boundaries would lead to $1.5 \%<$ $\varepsilon_{\text {plastic strain }}^{\text {total }}<35 \%$. This is a rough estimate. Nevertheless, it demonstrates that the observed microstructures show strain contributions that are of the same order of magnitude as those observed from macroscopic strains. A second occurrence is presented in Extended Data Figure 9 which shows evidence for grain boundary sliding from the displacements of the crystal-amorphous boundaries (see markers), and also from internal markers in the form of shear bands in the amorphous layer (black arrows). All evidence gives a consistent value for the displacement of $135 \mathrm{~nm}$ (leading to shear estimates more than twice larger than the one reported above). Note that, due to the shape of the grain, the displacement which is almost pure shear sliding in the upper part of the grain boundary transforms into opening in the central part.

\section{Glass transition temperature of intergranular thin films}

The $T_{g}$ of amorphous olivine may depend on the glass structure (configurational entropy), but also on the dimensions. The determination of Richet et $a l .{ }^{31}$ corresponds to a bulk material whereas in our case, thin intergranular amorphous films are constrained between two grains. In polymers, the $T_{g}$ of ultrathin films deviates significantly from the one of the bulk. As an example, for polystyrene with a bulk $T_{g} \approx 100^{\circ} \mathrm{C}, \Delta T_{g}=$ $-25^{\circ} \mathrm{C}$ for a $13 \mathrm{~nm}$ thick film on silicon oxide ${ }^{75}$.

\section{Data Availability}

The data of this manuscript are the micrographs and are present in the figures. Original files are available at https://doi.org/10.5281/zenodo.3893661

\section{References cited in the online Methods section}

63. Hiraga, T., Miyazaki, T., Tasaka, M., Yoshida, H. Mantle superplasticity and its self-made demise. Nature 468, 1091-1094 (2011) doi:10.1038/nature09685
64. Tasaka, M., Hiraga, T. \& Zimmerman, M.E. Influence of mineral fraction on the rheological properties of forsterite plus enstatite during grain-size-sensitive creep: 2. Deformation experiments. J. Geophys. Res. 118, 3991-4012 (2013)

65. Gasparik T. Phase diagrams for geologists, an atlas of Earth Interior, Springer-Verlag, Berlin-Heidelberg, p. 462. (2003)

66. Chen C.-H, Presnall, D. The system $\mathrm{Mg}_{2} \mathrm{SiO}_{4}-\mathrm{SiO}_{2}$ at pressure up to 25 kilobars. Am. Min., 60, 5-6, 398-406 (1975)

67. Paterson, M.S. Rock deformation experimentation, in: Duba, A., et al (Eds.), The Brittle-Ductile Transition in Rocks: the Head Volume. Geophys. Monogr. Ser., AGU, Washington D.C., pp. 187-194 (1990)

68. Thieme, M., Demouchy, S., Mainprice, D., Barou, F. \& Cordier, P. Stress evolution and associated microstructure during transient creep of olivine at 1000-1200 ${ }^{\circ}$ C. Phys. Earth Planet. Int. 278, 34-46 (2018) doi:10.1016/j.pepi.2018.03.002

69. Mei, S. \& Kohlstedt, D.L. Influence of water on the plastic deformation of olivine aggregates: 1. Diffusion creep regime. J. Geophys. Res. 105, 21-457-21-469 (2000)

70. Fei, H., Hegoda, C., Yamazaki, D. , W. M, Yurimoto, H., Shcheka, S. \& Katsura, T. High silicon selfdiffusion coefficient in anhydrous forsterite. Earth Planet. Sci. Lett., 345, 95 (2012)

71. Guignard, J., Bystricky, M., \& Béjina, F. Dense finegrained aggregates prepared by spark plasma sintering (SPS), an original technique in experimental petrology. Eur. J. Mineral, 23, 323-331 (2011)

72. Manthilake, M. A.G.M., Walter, N., \& Frost, D.J. A new multi-anvil press employing six independently acting $8 \mathrm{MN}$ hydraulic rams. High Pressure Research, 32-2, 195-207 (2012)

73. Vastava, R.B. \& Langdon, T.G. An investigation of intercrystalline and interphase boundary sliding in the superplastic $\mathrm{Pb}-62 \%$ Sn eutectic. Acta Metall. 27, 251257 (1979) https://doi.org/10.1016/00016160(79)90103-2

74. Langdon, T.G. The Effect of Surface Configuration on Grain Boundary Sliding. Metall. Trans. 3, 797-801 (1972). https://doi.org/10.1007/BF02647651

75. Fryer, D.S., Nealey, P.F. \& de Pablo, J.J. Thermal Probe Measurements of the Glass Transition Temperature for Ultrathin Polymer Films as a Function of Thickness. Macromolecules, 33(17), 6439-6447 (2000) https://doi.org/10.1021/ma0003349 


\section{Extended data figures}

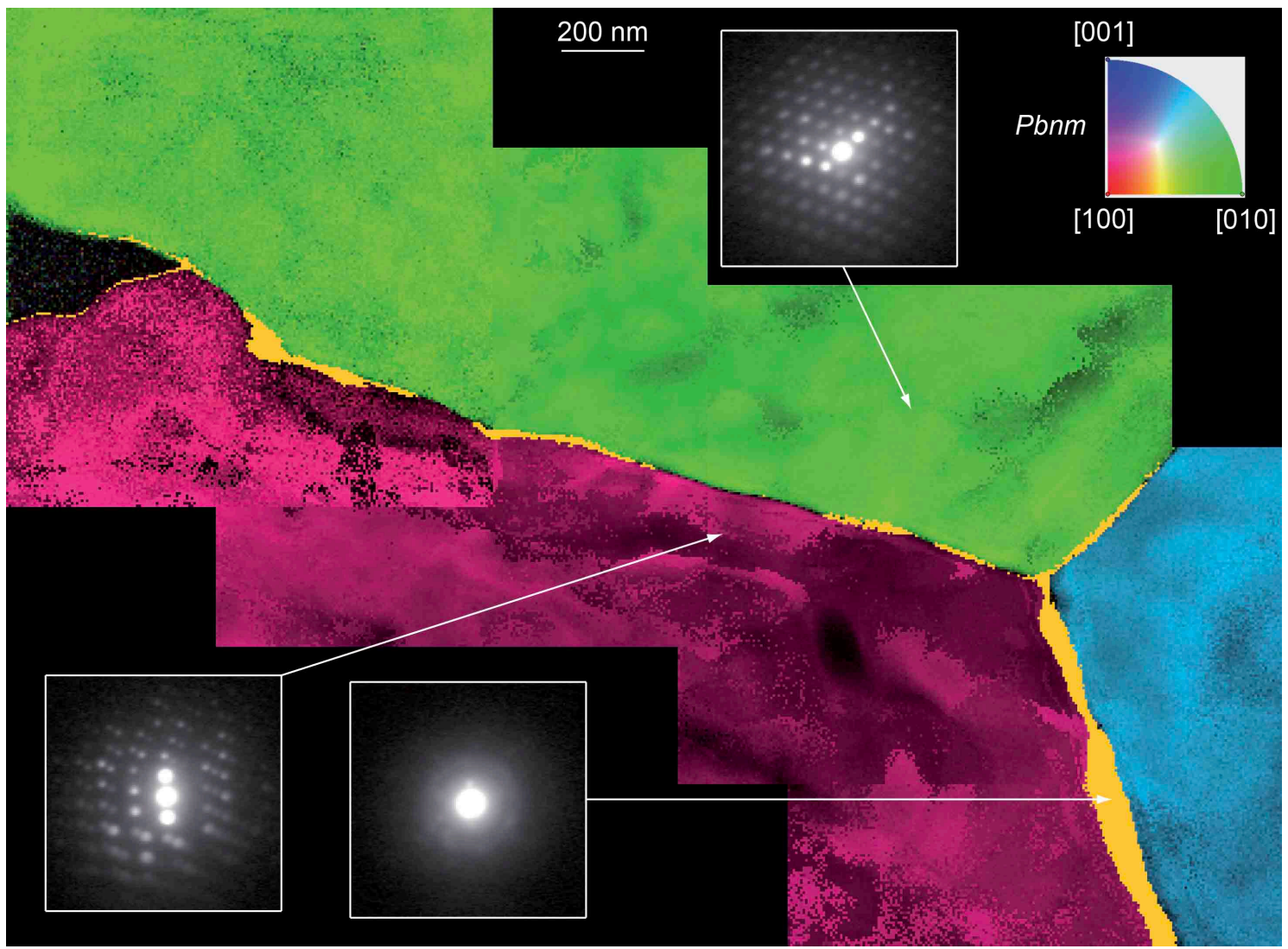

Extended Data Figure 1: Orientation map obtained in TEM using the ACOM-TEM method. The spatial resolution is $6 \mathrm{~nm}$. The three crystalline grains (red, blue and green) have been indexed with forsterite (Pbnm space group, two diffraction patterns are provided). The figure is the combination of the reliability map (darker areas being less well indexed) with the inverse pole figure along the vertical direction (using the color code shown in the insert). In between the grains is an amorphous phase which has been represented in orange with no relation with the color code of forsterite orientations 

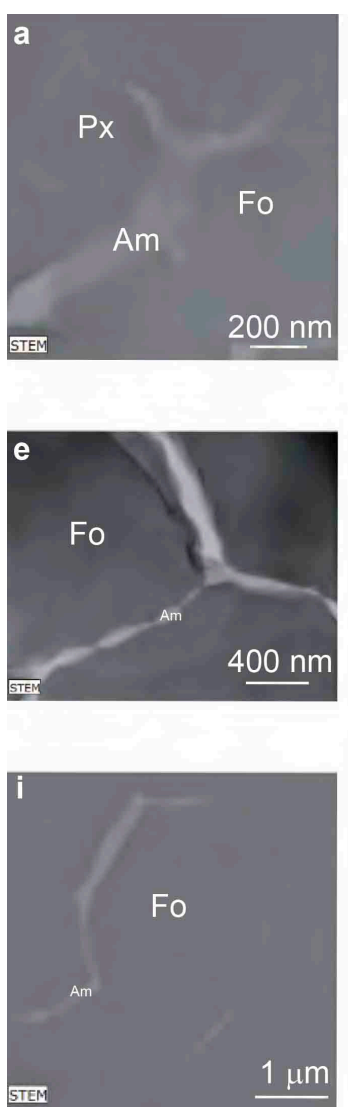
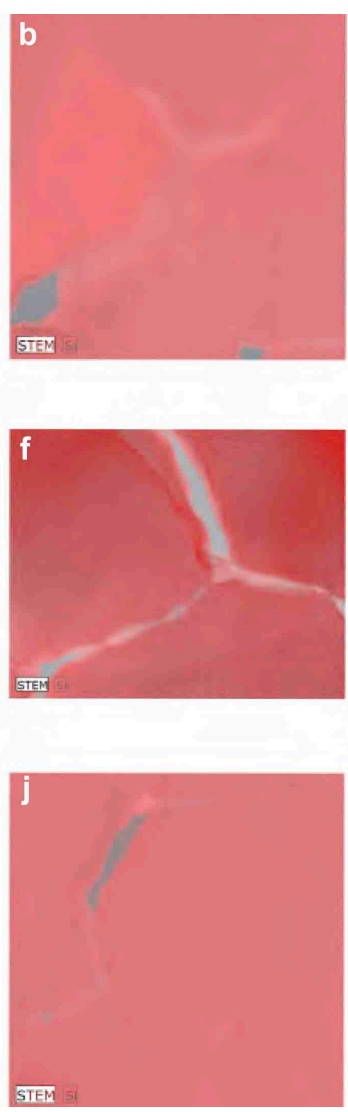
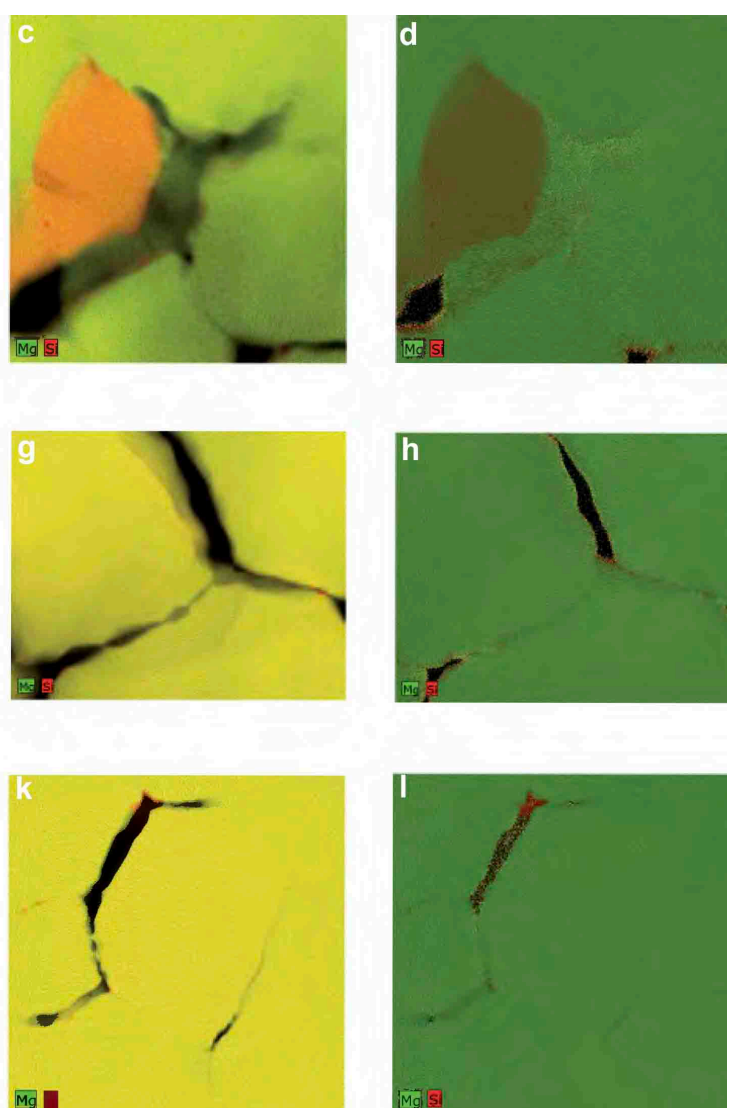

Extended Data Figure 2: Chemical analysis (STEM-EDX) of the intergranular amorphous phase in specimen NF1050-1. a, e, i) STEM-BF images. b, f, j) Combined STEM and chemical Si maps showing the presence of silicon in the amorphous phase. c, g, k) Combined $\mathrm{Si}$ and $\mathrm{Mg}$ maps showing continuity of composition $(\mathrm{Mg}, \mathrm{Si})$ between the forsterite grains and the amorphous phase. The Mg enrichment of the pyroxene grain appears. d, h, i ) Combined Si and Mg maps after quantification performed using the method of Van Cappellen and Doukhan (1994) on the basis of the stoichiometric oxides, where standard specimens were used to obtain the k-factors (Cliff \& Lorimer, 1975) of Mg and Si. In d) where the amorphous layer is larger, the thickness correction can be done accurately showing that the amorphous phase has exactly the composition of forsterite. In $h$ ) and i), the amorphous layers are smaller, thinner, with non-homogeneous thicknesses rendering quantification less reliable so the local deviations observed in the thinnest regions should be taken with care. 


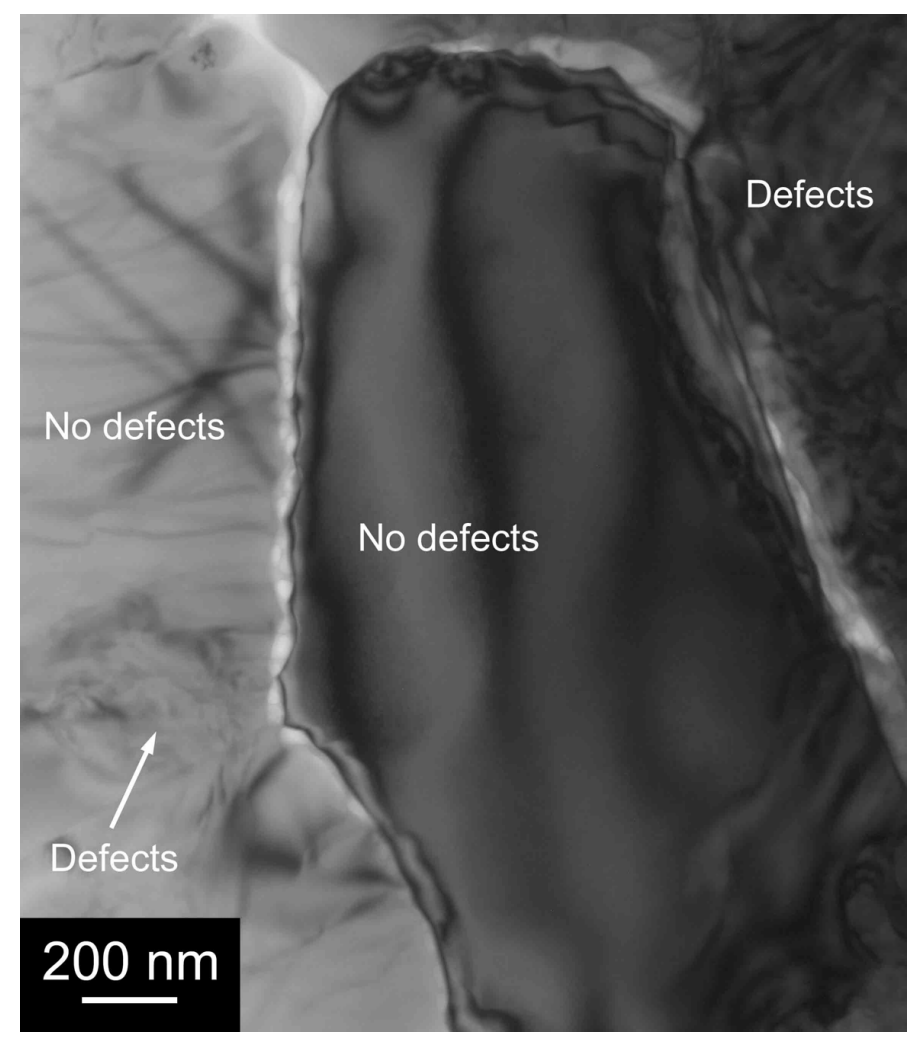

Extended Data Figure 3: specimen NF1050-1. Despite extensive serration of the vertical grain boundary, the forsterite grain in the middle (in Bragg conditions) shows no dislocation activity (no defects). The grain on the left shows only indications of strain due to defects where indicated by the arrow. 


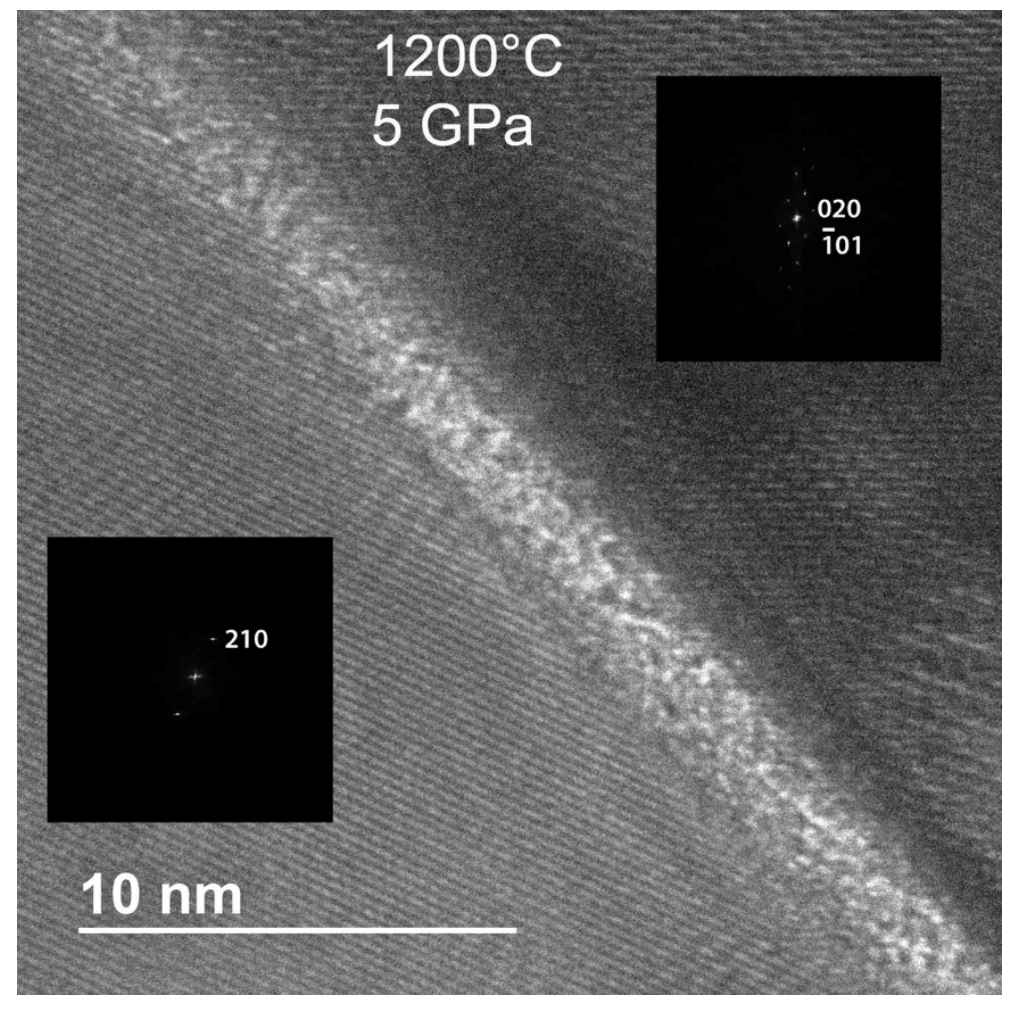

Extended Data Figure 4: HRTEM micrograph of an amorphous layer in a grain boundary. Experiment M639 deformed in the multi-anvil press at $1200^{\circ} \mathrm{C}, 5 \mathrm{GPa}$. 

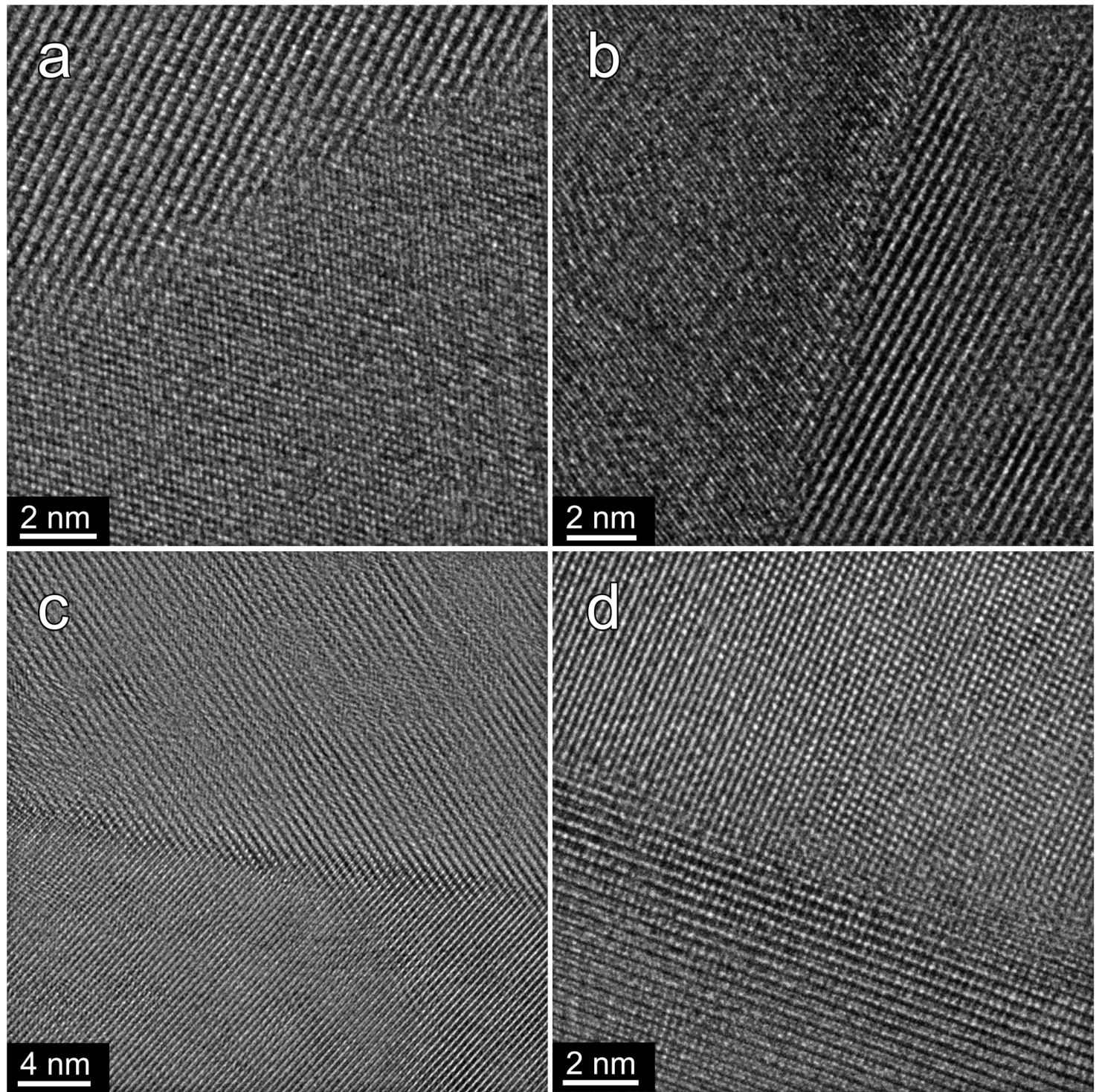

Extended Data Figure 5 : Grain boundaries of undeformed samples a-d) HRTEM of a grain boundary in the starting material used in Gasc et al. (2019) prior deformation experiments in the Paterson press. 


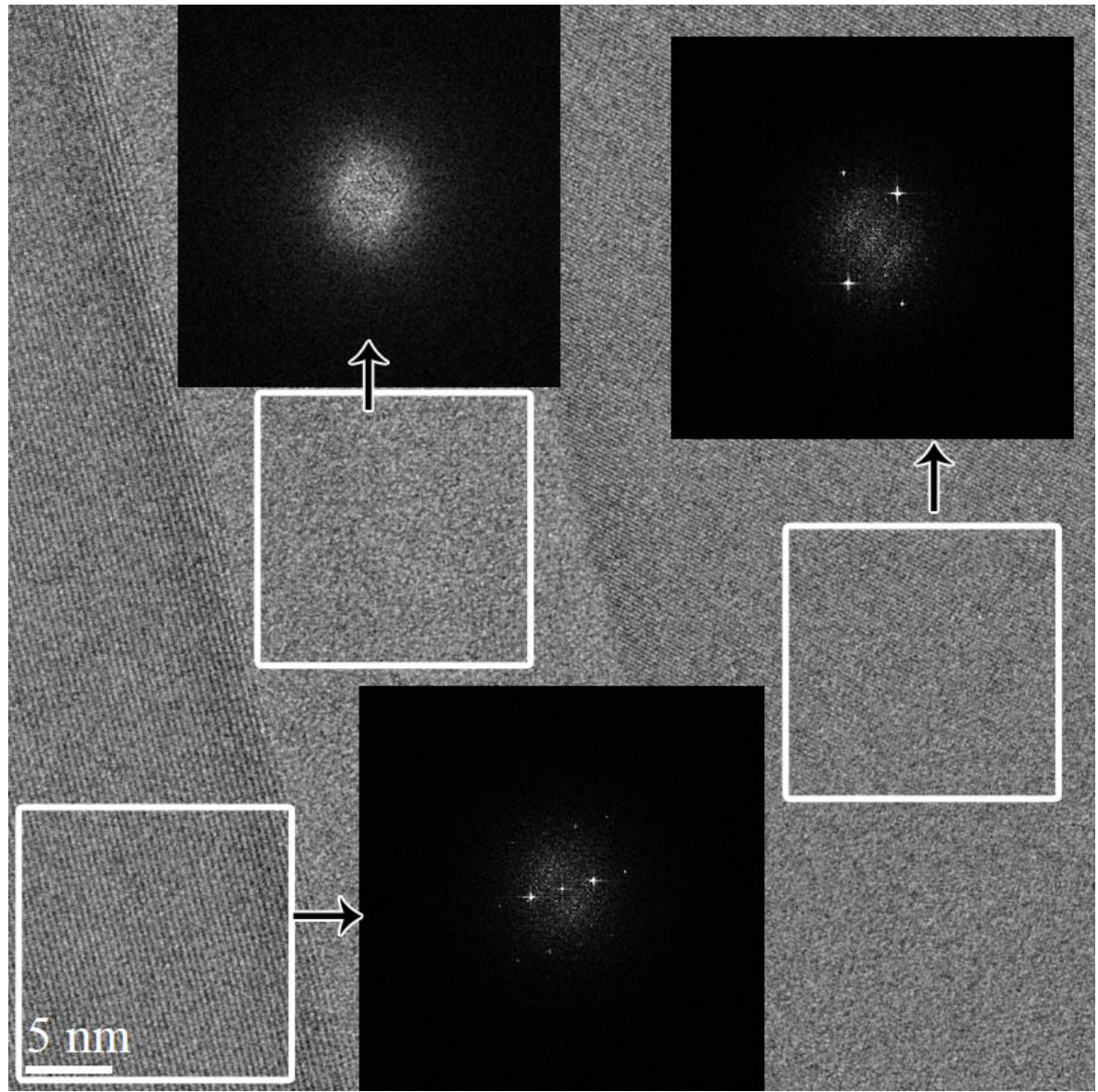

Extended Data Figure 6: Specimen M576. HRTEM of a grain boundary showing an amorphous layer; the FFTs from different regions are presented in insets. 

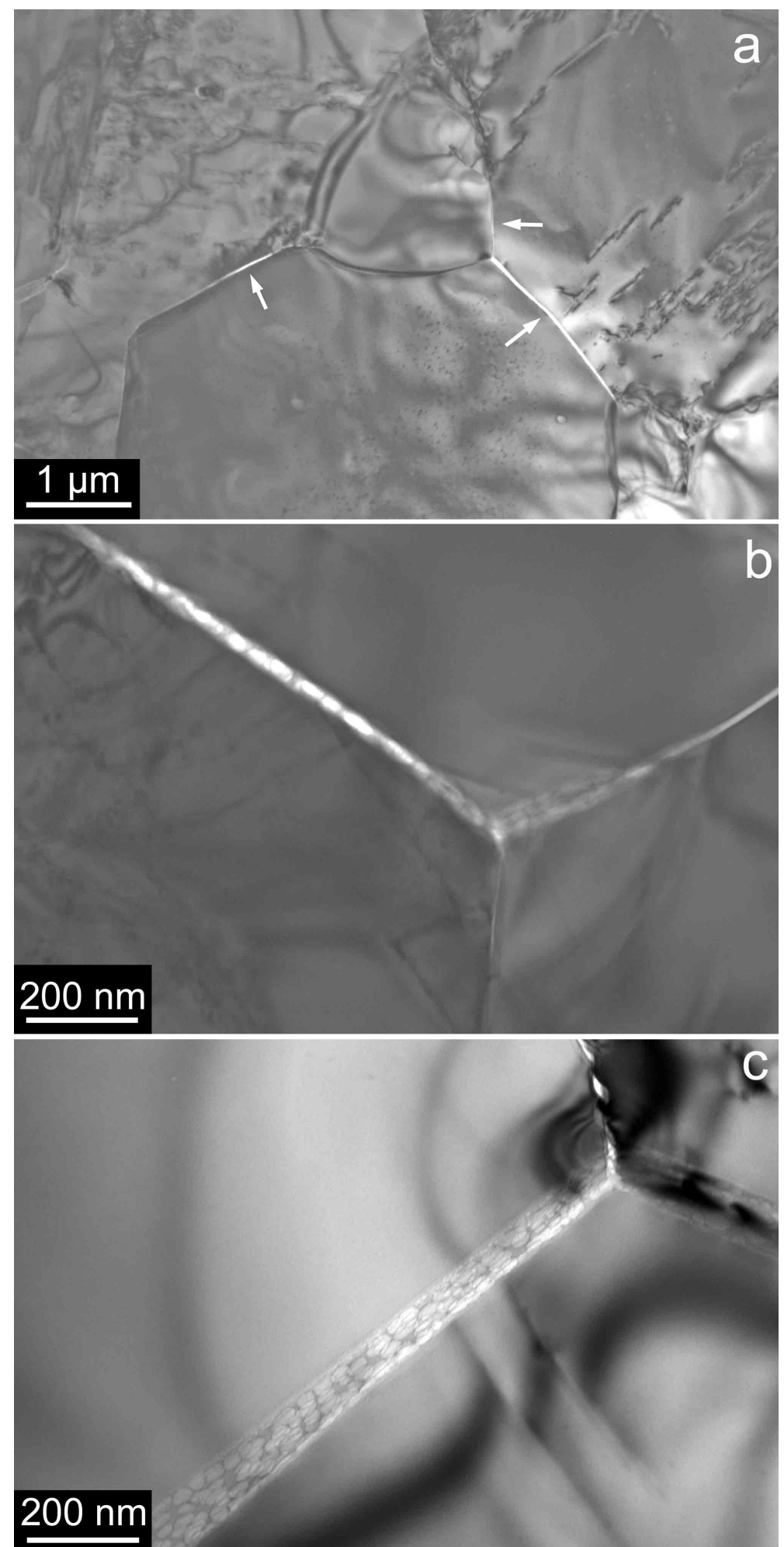

Extended Data Figure 7: CTEM of grain boundaries in specimen NF950-1. a) Evidence for cleavage-like intergranular fracturing (arrowed boundaries) ; b) Some grain boundaries display evidence for internal flow-like structure ; c) Inclined view of such boundary showing the cellular structures inside the boundary. At this temperature, the displacements remain very small. 

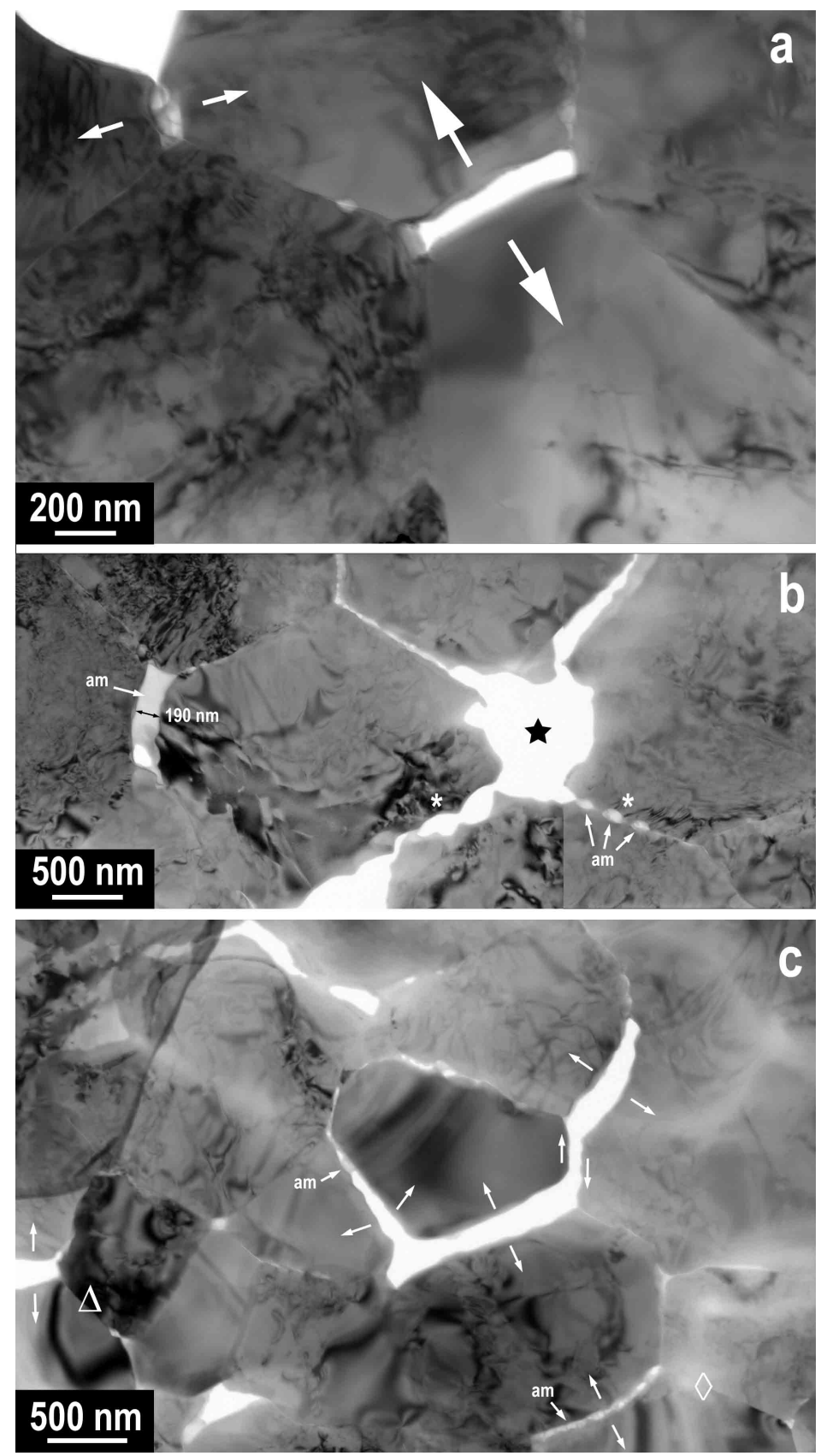

Extended Data Figure 8: Evidence of grain boundary sliding in specimen NF1050-1. CTEM images. a) Arrows indicate where grain boundary opening occurs in response to tensile stress components. These displacements must be accompanied by some shear along the neighboring boundaries. Without markers, these shear displacements cannot be quantified. b) is an assemblage of two micrographs. This region which was probably under horizontal tensile loading shows large displacements along vertical boundaries. Note that due to differential ion thinning rates between crystalline and amorphous materials, the region with the black star shows no remaining amorphous material (as in a)). In the boundary on the left located in a thicker region, some amorphous olivine (am) is preserved. The extensional displacement at this boundary (ca. $190 \mathrm{~nm}$ ) is used in the Methods section to evaluate the local strain. The boundaries indicated by the white asterisks show strong morphological evidence of ductile flow. The one on the right is still filled with amorphous olivine. c) The grain at the center was probably subjected to complex triaxial loading which has been accommodated by amorphization (some is remaining: "am") and flow involving rotational, tensile and shear components (arrows). On the bottom right is a grain boundary still filled with amorphous material under tensile loading. The neighboring grain boundary (white diamond) must also have experienced some shear. This is also probably the case for the boundary $(\Delta)$ that is close to an opening boundary. 


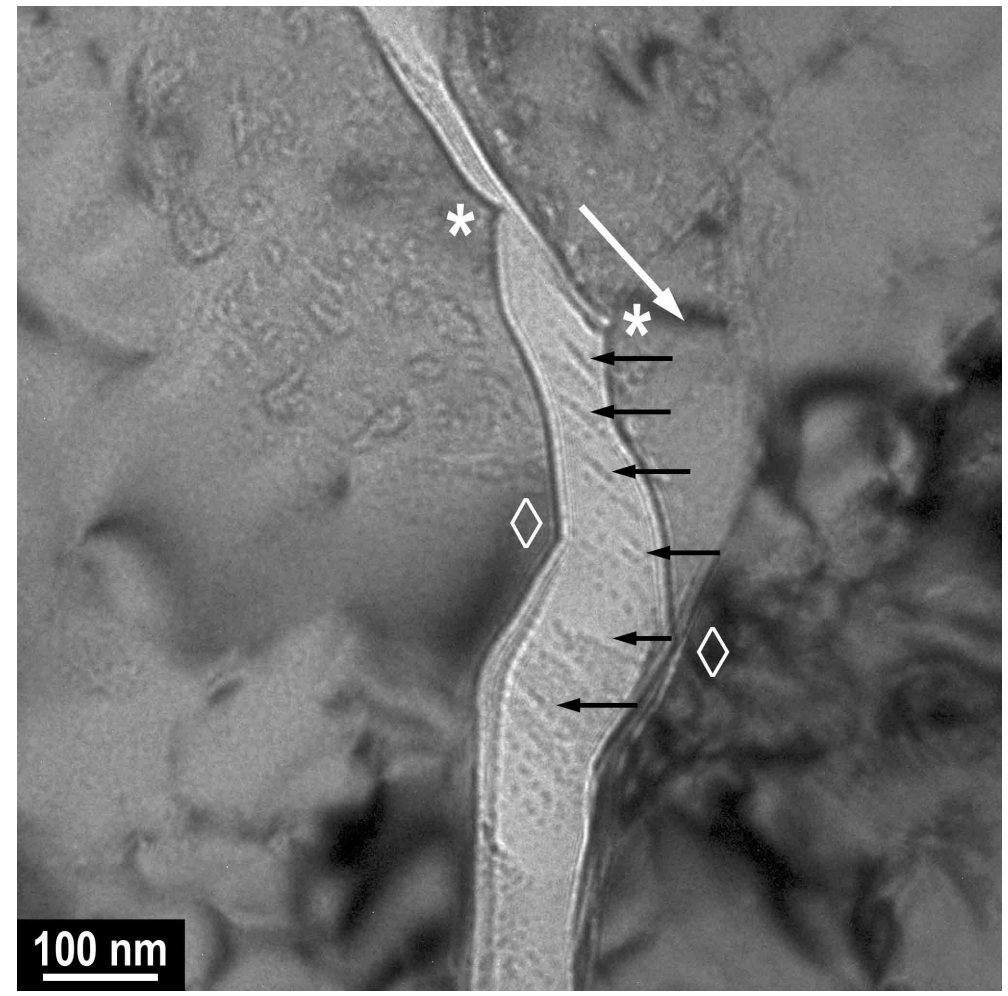

Extended Data Figure 9: Evidence of grain boundary sliding in specimen M640 (5 GPa, $\left.1000{ }^{\circ} \mathrm{C}\right)$. Fresnel $(\Delta \mathrm{f} \sim$ $20 \mu \mathrm{m}$ ) micrograph. The symbols represent markers which help to visualize the shear (represented by the vector (white arrow)). Note also the shear bands evidenced by the Fresnel contrast and shown by some black arrows. Due to the shape of the grain, the pure shear sliding displacement in the upper part of the grain boundary transforms into opening in the central part. 